\title{
Pengetahuan Lokal Masyarakat Kepulauan Tentang Tumbuhan Anti-nyamuk
}

\author{
Said Hasan', Dharmawaty M. Taher ${ }^{2}$, M. Nasir Tamalene ${ }^{3}$ \\ ${ }^{1}$ Biology education magister program, PPS, Universitas Khairun, Indonesia, Email: saidhasan1965@gmail.com \\ 2 Biology education study program, FKIP, Universitas Khairun, Indonesia, Email: dharmawaty_2301@gmail.com \\ ${ }_{3}^{3}$ Biology education study program, FKIP, Universitas Khairun, Indonesia, Email: hannakhairunnisa@gmail.com
}

$\begin{array}{ll}\text { Received } & : 22-01-2020 \\ \text { Accepted } & : 12-05-2020 \\ \text { Available online } & : 28-05-2020\end{array}$

\begin{abstract}
ABSTRAK
Pemanfaatan bahan alami dari tanaman lokal sebagai anti-nyamuk dimulai dari pendalaman informasi tentang pengetahuan lokal masyarakat. Upaya ini perlu dilakukan untuk mengatasi beberapa permasalahan dari penggunaan anti-nyamuk sintetik yang beredar di pasaran, juga sebagai bagian dari upaya melestarikan kearifan lokal masyarakat yang mulai tergerus oleh kemajuan zaman. Tujuan penelitian ini adalah untuk mendeskripsikan pengetahuan lokal masyarakat kepulauan tentang pemanfaatan tumbuhan anti-nyamuk dan menganalisis potensi tumbuhan yang paling banyak digunakan masyarakat di wilayah kepulauan sebagai produk lotion anti-nyamuk. Metode yang digunakan adalah metode survei eksploratif. Pengumpulan data dilakukan dengan teknik wawancara, observasi secara mendalam terhadap informan dan dokumentasi. Data jenis tumbuhan anti-nyamuk yang paling banyak digunakan dianalisis komponen fitokimia. Hasil penelitian menunjukkan terdapat 9 jenis tumbuhan anti-nyamuk yang digunakan masyarakat yaitu Tagetes erecta L., Lavandula L., Cymbopogon citratus, Citrus aurantifolia, Syzygium aromaticum, Evodia suaveolens, Catharanthus roseus (L) G. Don., Alphitonia incana BL. dan Polygala paniculata. Jenis Alphitonia incana BL paling banyak digunakan masyarakat dan mengandung senyawa fitokimia alkaloid, terpenoid, flavonoid, fenolik dan tanin. Jenis Alphitonia incana BL berpotensi untuk dikembangkan sebagai produk lotion anti-nyamuk.
\end{abstract}

Kata Kunci: tumbuhan anti-nyamuk; masyarakat kepulauan, pengetahuan lokal

\begin{abstract}
The Utilization of natural materials from local plants as mosquito repellent starts from the deepening of information about local knowledge of the community. Research about antimosquito is important to overcome problems of the use of synthetic anti-mosquitoes on the market; besides that, this is also to preserve the community's local wisdom. The purpose of this study is to describe the local knowledge of the island community about the use of anti-mosquito plants and analyze the potential of plants that are most widely used by people in the islands as anti-mosquito lotion products. The method used is the exploratory survey method. Data collection is done by interviewing techniques, in-depth observation of informants, and documentation. The most used anti-mosquito plant data were analyzed by phytochemical components. The results showed that there were 9 species of anti-mosquito plants used by the community, namely Tagetes erecta L., Lavandula L., Cymbopogon citratus, Citrus aurantifolia, Syzygium aromaticum, Evodia suaveolens, Catharanthus roseus (L) G. Don., Alphitonia incana BL., and Polygala paniculata. Alphitonia incana BL is the most widely used type of society and contains phytochemical compounds, alkaloids, terpenoids, flavonoids, phenolics, and tannins. The Alphitonia incana BL., has the potential to be developed as an anti-mosquito lotion product.
\end{abstract}

Keywords: anti-mosquito plants; island community, local-wisdom 


\section{PENDAHULUAN}

Indonesia adalah negara yang mempunyai iklim tropis sehingga kondisi ini memberikan peluang sebagai tempat yang baik bagi perkembangbiakan nyamuk. Nyamuk merupakan salah satu vektor penyakit pada manusia. Gigitan nyamuk tidak hanya menimbulkan rasa nyeri dan pada beberapa kasus dapat menimbulkan reaksi alergi, tetapi juga mampu menyebarkan penyakit pada manusia (Abdel-Motagaly et al., 2017; Kausar 2018).

Masyarakat perkotaan dan pedesaan saat ini mulai melakukan upaya perlindungan diri dari bahaya gigitan nyamuk dengan cara seperti penggunaan anti-nyamuk bakar, aerosol, dan produk anti-nyamuk lainnya. Formulasi produk anti-nyamuk yang digunakan untuk mencegah gigitan nyamuk di pasaran saat ini adalah bentuk minyak, lotion dan krim. Produk anti-nyamuk umumnya mengandung DEET (Diethyltoluamide), dimetil-falat dan iridin (Raina, 2011). Penggunaan DEET dengan konsentrasi yang tinggi dilaporkan banyak memiliki efek samping seperti gejala hipersensitifitas, iritasi dan urtikaria. Setelah penggunaan yang berulang dan dalam jangka waktu lama, absorbsi melalui kulit dapat menyebabkan keracunan sistemik. Hal ini terutama terjadi pada anak-anak (Qiu et al., 1998).

Salah satu antisipasi penting yang perlu dilakukan untuk mengatasi persoalan ini adalah dengan menggunakan anti-nyamuk dari bahan alami. Pemanfaatan tumbuhan anti-nyamuk secara alami menjadi pilihan masyarakat karena bahan tersebut banyak terdapat di sekitar pemukiman serta aman digunakan dalam jangka panjang (Raina, 2011). Penggunaan bahan alami sebagai anti-nyamuk merupakan langkah praktis dan ekonomis untuk mencegah penyakit-penyakit yang ditularkan oleh nyamuk ke manusia.

Daerah Maluku Utara banyak memiliki potensi sumberdaya alam tumbuhan yang biasanya dimanfaatkan sebagai bahan obat. Pemanfaatan tumbuhan sebagai bahan obat secara tradisional dikenal dengan istilah (Rorano). Beberapa penelitian telah melaporkan adanya penggunaan tanaman lokal dan kandungan senyawanya yang terbukti efektif sebagai bahan obat diantaranya cengkeh varietas Afo dari Ternate sebagai larvasida terhadap nyamuk Aedes aegypti (Taher et al., 2015) dan sebagai antimalaria (Taher et al., 2019). Pengetahuan masyarakat lokal tentang Rorano secara turun-temurun patut mendapat perhatian untuk dilestarikan terutama melalui berbagai kajian dan penelitian. Salah satunya yaitu dengan melakukan kajian pengetahuan masyarakat lokal kepulauan tentang tanaman anti-nyamuk. Banyak jenis tanaman yang menurut masyarakat lokal kepulauan telah dimanfaatkan sebagai tanaman anti-nyamuk yang belum diteliti lebih lanjut.

Beberapa tanaman yang telah dimanfaatkan sebagai anti-nyamuk diantaranya adalah yang mengandung minyak atsiri. Minyak atsiri merupakan metabolit sekunder dari tanaman yang bersifat mudah menguap atau volatil dan dapat ditemukan di seluruh bagian tanaman seperti buah, biji, daun, bunga, batang, kulit kayu, akar maupun rimpang (Rialita et al. 2015). Mekanisme minyak atsiri sebagai pengusir nyamuk adalah dengan cara pelepasan bau yang menyengat sehingga menimbulkan efek tidak disukai nyamuk. Senyawa yang dihasilkan tumbuhan ini selanjutnya dimanfaatkan antara lain sebagai lotion anti-nyamuk yang dioleskan di kulit untuk menghindari gigitan nyamuk. Ketertarikan nyamuk dalam mencari makan dipicu oleh adanya karbondioksida, panas tubuh, dan bau kulit yang berpotensi menjadi sumber darah. Menurut Boesri et al. (2015), kulit manusia mengeluarkan asam laktat dan produk ekskresi yang menimbulkan bau sehingga mudah terdeteksi oleh nyamuk. 
Pemanfaatan tanaman anti-nyamuk yang akan diolah lebih lanjut sebagai bahan produk yang ramah lingkungan dimulai dari langkah mengeksplorasi pengetahuan masyarakat lokal khususnya di wilayah kepulauan tentang pemanfaatan tanaman anti-nyamuk. Upaya ini penting dilakukan selain sebagai bagian dari upaya pemanfaatan bahan alami dari tanaman untuk menghindari efek bahaya residu dari penggunaan bahan sintetis, juga sebagai upaya untuk melestarikan kearifan lokal masyarakat kepulauan yang mulai tergerus oleh kemajuan zaman. Tujuan penelitian ini adalah untuk mendeskripsikan pengetahuan lokal masyarakat kepulauan tentang pemanfaatan tumbuhan anti-nyamuk dan menganalisis potensi tumbuhan yang paling banyak digunakan masyarakat di wilayah kepulauan sebagai produk lotion antinyamuk.

\section{METODE PENELITIAN}

Penelitian ini menggunakan metode survei eksploratif. Pengumpulan data dilakukan dengan teknik wawancara, observasi secara mendalam terhadap informan dan dokumentasi mengenai jenis-jenis tanaman anti-nyamuk. Data penelitian ditabulasi secara sistematis dalam bentuk tabel yang memuat nama family, nama lokal, nama indonesia, dan nama ilmiah setiap jenis yang ditemukan. Analisis pemanfaatan tanaman obat dengan menggunakan Nilai Tingkat Kesetiaan (FL) yang diketahui melalui informasi penggunaan tanaman tertentu untuk tujuan utama yang sama dihitung sesuai dengan rumus berikut.

$$
\text { FL }(\%)=\frac{\text { Ip }}{\text { Iu } 100}
$$

Dimana Ip adalah jumlah informan yang secara independen menyarankan penggunaan spesies tanaman anti-nyamuk dan Iu adalah jumlah total informan yang menyebutkan tanaman yang sama yaitu tanaman anti-nyamuk.

Selanjutnya, tanaman yang paling banyak digunakan sebagai anti-nyamuk oleh masyarakat kepulauan diekstraksi dan dilanjutkan dengan melakukan analisis kandungan fitokimia. Analisis fitokimia mengacu pada prosedur menurut Harborne (1987). Prosedur analisis meliputi:

\section{Uji Flavonoid dan Fenol}

Ekstrak aktif sebanyak $0.1 \mathrm{~g}$ dilarutkan dengan kloform: air $1: 1$ kemudian dikocok dan didiamkan hingga terbentuk 2 lapisan. Lapisan atas dibagi 2 untuk uji flavonoid dan fenol. Uji flavonoid dilakukan dengan menambahkan $0.1 \mathrm{~g}$ logam $\mathrm{Mg} ; 1 \mathrm{~mL} \mathrm{HCl}$ pekat dan $1 \mathrm{~mL}$ alkohol. Uji positif flavonoid apabila terbentuk warna kuning atau jingga. Uji fenol dilakukan dengan menambahkan $\mathrm{FeCL}_{3}$ 1\% dan positif fenol apabila terbentuk warna hijau atau biru/ungu.

\section{Uji Alkaloid}

Ekstrak aktif sebanyak $0.1 \mathrm{~g}$ ditambahkan $10 \mathrm{~mL}$ kloroform-amonia $10 \%$ dan disaring. Filtrat ditetesi dengan $\mathrm{H}_{2} \mathrm{SO}_{4} 2 \mathrm{M}$, dikocok kemudian ditambahkan hingga terbentuk 2 lapisan. Lapisan asam (lapisan atas yang tidak berwarna) diteteskan ke lempeng atas dan ditambahkan beberapa tetes pereaksi Mayer, Wagner, dan Dragendorf. Uji positif alkaloid berturut-turut menghasilkan endapan berwarna putih kekuningan, coklat, dan jingga. 


\section{Uji Saponin dan Tanin}

Ekstrak aktif sebanyak 0.1 gr dilarutkan dengan kloroform: air (1:1) kemudian dikocok dan didiamkan hingga terbentuk 2 lapisan. Lapisan bawah disaring, residunya dimasukkan ke dalam gelas piala, kemudian ditambahkan $5 \mathrm{~mL}$ aquades. Larutan dipanaskan hingga mendidih selama 5 menit, kemudian dimasukkan ke dalam 2 tabung reaksi. Larutan pada tabung pertama dikocok secara vertikal sampai terbentuk buih, kemudian didiamkan selama 10 menit. Larutan ditambahkan $\mathrm{HCl} 2 \mathrm{~N}$ kemudian didiamkan. Apabila buih tidak berubah maka positif terdapat saponin. Larutan ke 2 ditambahkan $\mathrm{FeCl}_{3} 1 \%$. Apabila warna menjadi biru atau hitam kehijauan maka positif terdapat tanin.

\section{Uji Terpenoid dan Steroid}

Sebanyak $0.1 \mathrm{~g}$ ekstrak aktif dilarutkan dengan kloroform-air (1:1) kemudian dikocok dan diendapkan hingga terbentuk 2 lapisan. Lapisan bawah disaring, filtratnya diteteskan ke lempeng tetes, dikeringkan dan ditambahkan pereaksi Lieberman-Buchard. Jika terbentuk warna merah/ungu, maka ekstrak positif mengandung triterpenoid, jika terbentuk warna hijau/biru maka positif steroid.

\section{HASIL DAN PEMBAHASAN}

\section{Jenis-jenis Tumbuhan Anti-nyamuk}

Berdasarkan hasil wawancara yang dilakukan pada masyarakat lokal di wilayah kepulauan yaitu di Desa Tabadamai, Desa Braha, Desa Bobaneigo, dan Desa Sondo-sondo, Kabupaten Halmahera Barat, diperoleh hasil jenis-jenis tumbuhan anti-nyamuk sebanyak 9 jenis. Data tumbuhan disajikan pada Tabel 1.

Tabel 1. Jenis-jenis tumbuhan anti-nyamuk yang digunakan masyarakat kepulauan

\begin{tabular}{llll}
\hline Family & Nama lokal & Nama Indonesia & Nama Ilmiah \\
\hline Asteracea & Bunga tahi ayam & Randa kencana & Tagetes erecta L. \\
Apocynaceae & Bunga pica piring & Tapak dara & Catharanthus roseus (L) G. Don \\
Lamiacea & Bunga lavender & Lavender ungu & Lavandula L. \\
Myrtaceae & Cengkeh & Cengkeh & Syzygium aromaticum L. \\
Rutaceae & Zodia & Zodia & Evodia suaveolens \\
Rutaceae & Lemon nipis & Jeruk nipis & Citrus aurantifolia \\
Rhamnaceae & Sabo & Numbai & Alphitonia incana BL. \\
Poaceae & Garamakusu & Sereh wangi & Cymbopogon citratus \\
Polygalaceae & Akar Balsem & Akar Wangi & Polygala paniculata \\
\hline
\end{tabular}

Diantara 9 family tanaman penolak nyamuk yang ditemukan, terdapat family Asteraceae dan Lamiaceae. Menurut Tefera \& Kim (2019), dari 8 spesies tanaman penolak nyamuk yang ditemukan di Ethopia Afrika, terdapat dua diantaranya adalah dari family Asteraceae dan Lamiaceae. Hasil yang sama juga dikemukakan oleh Kantheti \& Padma (2017) untuk tanaman penolak nyamuk di India.

Bagian vegetatif dan generatif tumbuhan anti-nyamuk yang digunakan oleh masyarakat Desa Tabadamai, Desa Braha, Desa Bobaneigo, dan Desa Sondo-sondo bervariasi yaitu bagian vegetatif yang digunakan adalah batang, daun, dan akar, serta organ generatif berupa buah dan bunga. Jenis tumbuhan anti-nyamuk yang ditemukan di masing-masing desa memiliki 
nilai pemanfaatan yang berbeda-beda. Bagian tumbuhan anti-nyamuk yang paling banyak dimanfaatkan berturut-turut yaitu bagian bunga, daun, dan tangkai. Deskripsi pemanfaatan berdasarkan bagian tumbuhan disajikan pada Gambar 1.

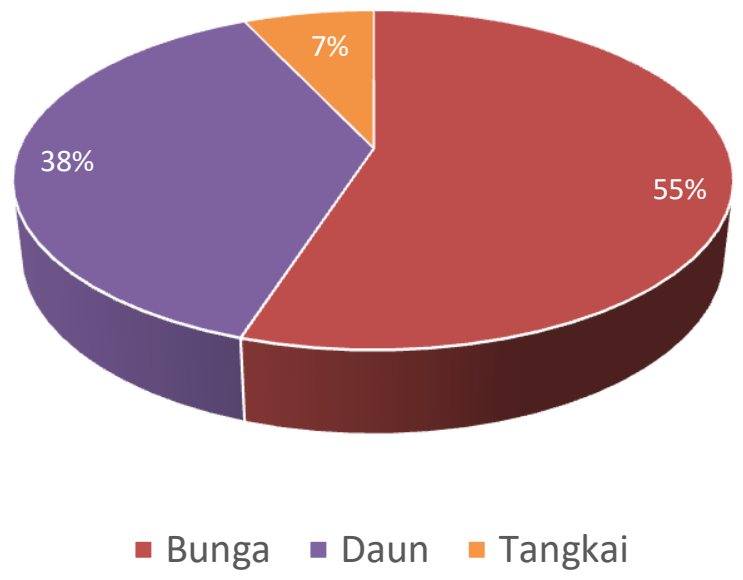

Gambar 1. Persentase Bagian Tubuh Tumbuhan Anti-nyamuk yang Dimanfaatkan Masyarakat

Tumbuhan berbunga paling banyak dimanfaatkan sebagai anti-nyamuk. Pemanfaatan ekstrak dari tumbuhan berbunga ini sebanyak $25 \%$ dari obat pengendalian penyakit dan vektor yang digunakan saat ini (Chalannavar et al. 2013).

\section{Pemanfaatan Tumbuhan Anti-nyamuk}

Pemanfaatan tanaman anti-nyamuk dilakukan oleh masyarakat kepulauan adalah dengan cara yang sangat sederhana yaitu diletakan di sudut-sudut ruangan dalam dalam rumah sebagai media pengusir nyamuk. Khusus di luar rumah, tumbuhan diletakkan dekat pintu, jendela atau lubang udara lainnya sehingga aroma tanaman terbawa angin masuk ke dalam ruangan. Cara yang sering dilakukan agar terhindar dari gigitan nyamuk yaitu mengoleskan bagian tumbuhan seperti kulit batang dan daun pada tubuh. Pada malam hari masyarakat sering membakar bagian-bagian tumbuhan untuk mengusir nyamuk. Adapun metode yang digunakan untuk mengusir nyamuk yang dideskripsikan pada Tabel 2.

Tabel 2. Bagian tumbuhan anti-nyamuk yang dimanfaatkan dan cara penggunaannya

\begin{tabular}{ll}
\hline Nama Ilmiah & \multicolumn{1}{c}{ Cara Penggunaan } \\
\hline Tagetes erecta L. & $\begin{array}{l}\text { Bunga ini ditanam di sekitar pekarangan rumah untuk mengusir nyamuk karena bunga } \\
\text { tanaman ini mengeluarkan aroma yang tidak disukai oleh nyamuk. }\end{array}$ \\
$\begin{array}{l}\text { Catharanthus } \\
\text { roseus } \text { (L) G. Don }\end{array}$ & $\begin{array}{l}\text { Tanaman ini di letakkan di sudut ruangan dalam rumah sebagai media pengusir nyamuk. } \\
\text { Sementara untuk di luar rumah di letakan dekat pintu, jendela atau lubang dara lainnya } \\
\text { sehingga aroma tanaman terbawa angina masuk ke dalam ruangan }\end{array}$ \\
& $\begin{array}{l}\text { Bunga dan daun tanaman di remas-remas kemuddian di oleskan ke kulit. Selain itu } \\
\text { penggunaan lainnya bisa dengan cara meletakkan tanaman di sudut-sudut ruangan dalam } \\
\text { rumah, sementara untuk penempatan di luar rumah diletakan dekat pintu, jendela atau } \\
\text { lubang udara lainnya sehingga aroma tanaman terbawa angina masuk ke dalam ruangan }\end{array}$
\end{tabular}




\begin{tabular}{|c|c|}
\hline $\begin{array}{l}\text { Syzygium } \\
\text { aromaticum }\end{array}$ & $\begin{array}{l}\text { Tangkai bunga tanaman cengkeh dikeringkan terlebih dahulu kemudian dibakar untuk } \\
\text { menghindari gigitan nyamuk }\end{array}$ \\
\hline Evodia suaveolens & $\begin{array}{l}\text { Tanaman ini bisa secara langsung digunakan dengan meremas-remas daun yang } \\
\text { kemudian di oleskan ke kulit untuk menghindari gigitan nyamuk. Selain itu penggunaan } \\
\text { lainnya bisa dengan cara meletakan tanaman di sudut-sudut ruangan dalam rumah, } \\
\text { sementara untuk penempatan di luar rumah di letakan dekat pintu, jendela atau lubang } \\
\text { udara lainnya sehingga aroma tanaman terbawa angina masuk ke dalam ruangan }\end{array}$ \\
\hline Citrus aurantifolia & $\begin{array}{l}\text { Masyarakat menggunakan daun kulit jeruk yang telah kering untuk mengusir nyamuk } \\
\text { dengan cara di bakar }\end{array}$ \\
\hline $\begin{array}{l}\text { Alphitonia incana } \\
\text { BL. }\end{array}$ & $\begin{array}{l}\text { Tumbuhan ini biasanya digunakan masyarakat dengan cara dikelupas kulit kayu, } \\
\text { dihancurkan dan kemudian dioleskan di bagian kulit. }\end{array}$ \\
\hline $\begin{array}{l}\text { Cymbopogon } \\
\text { citratus }\end{array}$ & $\begin{array}{l}\text { Tanaman ini ditanam di pekarangan rumah untuk mengusir nyamuk karena } \\
\text { mengeluarkan aroma yang tidak disukai oleh nyamuk }\end{array}$ \\
\hline $\begin{array}{l}\text { Polygala } \\
\text { paniculata }\end{array}$ & Tanaman ini diambil bagian akarnya, dihaluskan kemudian dioleskan pada kulit. \\
\hline
\end{tabular}

Hasil pada Tabel 2 menunjukkan cara memanfaatkan tanaman sebagai anti-nyamuk oleh masyarakat yang berbeda-beda, tergantung pada jenis tanaman dan bagian tanaman yang dimanfaatkan. Di Negara Kamerun, masyarakat lokalnya memanfaatkan daun dan kulit tumbuhan Canarium schweinfurthii (Burseraceae), Elaeis guineensis (Arecaceae), Chromolaena odorata (Compositae) dan Limon limon (Rutaceae) untuk mengusir serangga nyamuk (Youmsi et al., 2017). Beberapa tanaman anti-nyamuk di India dimanfaatkan masyarakat secara tradisional dengan cara dibakar, sehingga menghasilkan asap yang berfungsi untuk menghalau nyamuk. Tanaman tersebut yaitu Azadirachta indica, Citrus medica, Murraya koenigii, Ocimum tenuifloreum dan Ricinus communis (Shankar et al., 2013).

\section{Potensi Tumbuhan Alphitonia incana BL. sebagai Produk Lotion Anti-nyamuk}

Dari hasil penelusuran tercatat bahwa tumbuhan yang paling banyak dimanfaatkan masyarakat kepulauan ketika berada di hutan adalah kulit batang Alphitonia incana BL. Deskripsi tumbuhan Alphitonia incana BL., sebagaimana tersaji pada Gambar 2. 
Hasan, S., Taher, D.M., Tamalene, M.N. 2020. Tumbuhan anti-nyamuk, masyarakat kepulauan, pengetahun lokal

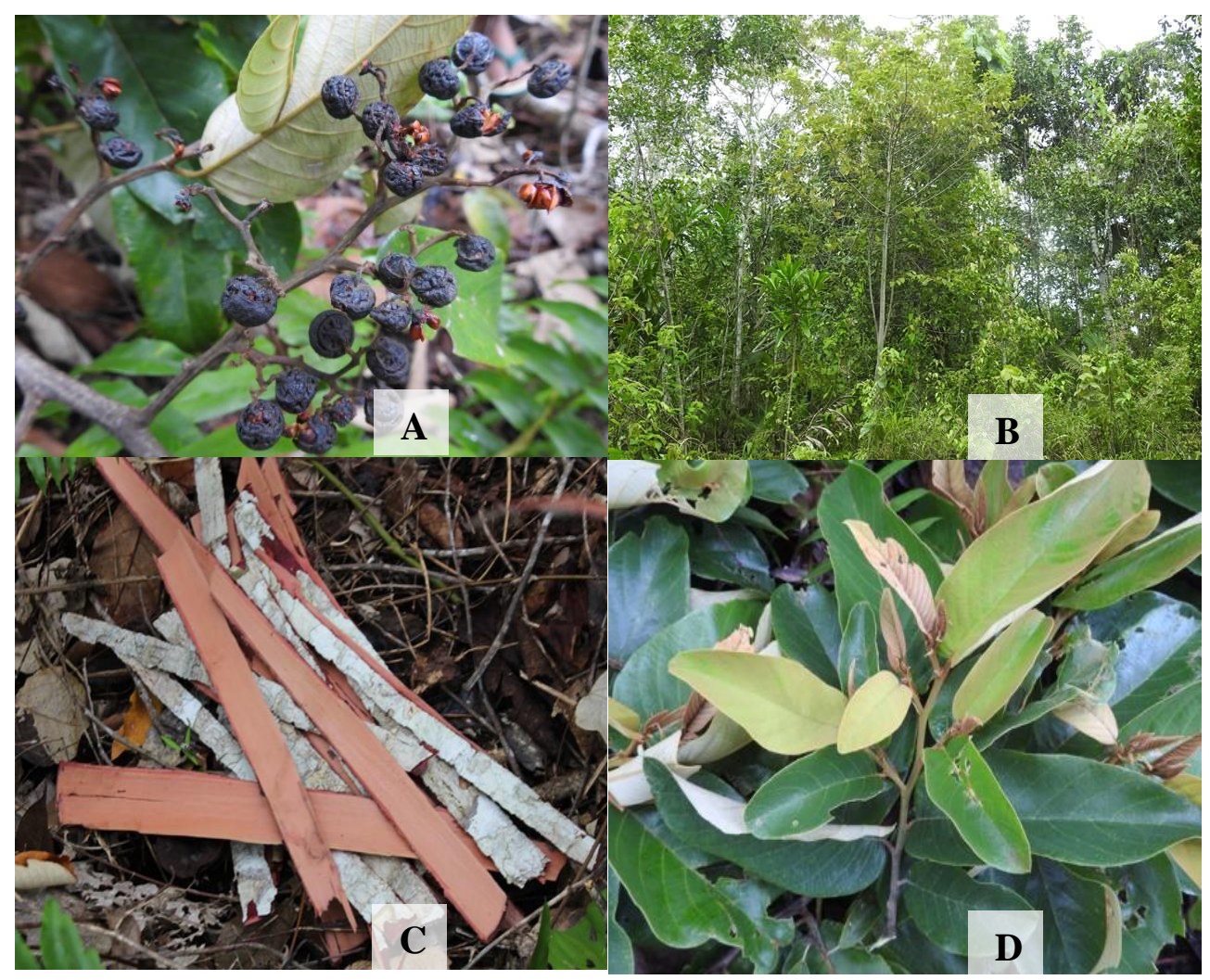

Gambar 2. Morfologi Tumbuhan Alphitonia incana BL. [A] Buah, [B] Perawakan pohon, [C] Kulit Batang, dan [D] Daun

Dari data hasil survei, selanjutnya dianalisis kandungan fitokimia batang tumbuhan Alphitonia incana BL. Analisis kandungan senyawa dilakukan di Laboratorium Kimia Organik Departemen Kimia IPB. Data hasil analisis disajikan pada Tabel 2.

Tabel 3. Kandungan senyawa fitokimia kulit batang tumbuhan Alphitonia incana BL.

\begin{tabular}{lll}
\hline Kandungan Senyawa & Hasil & Keterangan \\
\hline Alkaloid & ++ & Sedikit \\
Terpenoid & ++ & Sedikit \\
Flavanoid & +++ & Banyak \\
Fenolik & +++ & Banyak \\
Saponin & ++++ & Sangat Banyak \\
Steroid & - & Tidak ada \\
Tanin & ++++ & Sangat Banyak \\
\hline
\end{tabular}

Menurut Maia \& Moore (2011), penolak berbasis tumbuhan telah digunakan selama beberapa generasi dalam praktik tradisional sebagai langkah perlindungan pribadi terhadap nyamuk yang mencari inang. Pengetahuan tentang tanaman penolak nyamuk secara tradisional diperoleh melalui studi etnobotani merupakan sumberdaya berharga untuk pengembangan produk alami baru.

Kulit batang tumbuhan Alphitonia incana BL. diduga mengandung senyawa yang bersifat sebagai anti-nyamuk alami, karena terdapat kelompok senyawa fenolik, flavonoid dan tanin. Hal ini sebagaimana dikemukakan oleh Youmsi et al., (2017) dan Bekele (2018) bahwa 
kandungan senyawa pada tumbuhan yang berfungsi sebagai anti-nyamuk alami adalah kelompok senyawa fenolik, flavonoid dan tanin.

Menurut Pichersky \& Gershenzon (2002), sebagian besar tanaman mengandung senyawa yang digunakan untuk mencegah serangan dari serangga fitofag (pemakan tumbuhan). Senyawa kimia ini termasuk dalam beberapa kategori termasuk penolak, penghambat makan, racun, dan pengatur tumbuh. Sebagian besar dapat dikelompokkan menjadi lima kategori kimia utama: (1) senyawa nitrogen (terutama alkaloid), (2) terpenoid, (3) fenolik, (4) proteinase inhibitor, dan (5) regulator pertumbuhan. Meskipun fungsi utama dari senyawa ini adalah pertahanan terhadap serangga fitofag, banyak juga yang efektif melawan nyamuk dan diptera menggigit lainnya, terutama komponen volatil yang dikeluarkan.

\section{KESIMPULAN}

Jenis-jenis tumbuhan anti-nyamuk yang dimanfaatkan masyarakat wilayah kepulauan Halmahera yaitu; 1) Tagetes erecta L., Catharanthus roseus (L) G. Don., Lavandula L., Syzygium aromaticum L., Evodia suaveolens, Citrus aurantifolia, Alphitonia incana BL., Cymbopogon citratus, dan Polygala paniculata. Cara pemanfaatan tumbuhan anti-nyamuk dilakukan dengan cara dibakar untuk menghasilkan asap, dioles menggunakan bagian tumbuhan pada kulit tubuh, dan membudidayakannya di halaman rumah. Kulit batang tumbuhan Alphitonia incana BL. mengandung sejumlah senyawa yang bersifat anti-nyamuk yaitu fenolik, flavonoid, dan tanin sehingga berpotensi dikembangkan dalam produk sediaan berupa lotion anti-nyamuk.

\section{DAFTAR PUSTAKA}

Abdel-Motagaly, A.M.E., Mohamad H.M., Morsy T.A. 2017. A Mini-Review on Skeeter Syndrome or Large Local Allergy to Mosquito Bites. J Egyptian Soc Parasitol. Vol. 47(2) 415-424.

Boesri, H., Heriyanto B., Susanti L., Handayani S.W. 2015. Uji Repelen (Daya Tolak) Beberapa Ekstrak Tumbuhan Terhadap Gigitan Nyamuk Aedes aegypti Vektor Demam Berdarah Dengue. Vektora. 7 (2): 79 - 84

Bekele, D. 2018. Review on insecticidal and repellent activity of plant products for malaria mosquito control. Biomed Res Reviews. 2(2): 1-7

Chalannavar, R.K., Hurinanthan V., Singh A., Venugopala, K.N., Gleiser R.M., Baijnath H., Odhav B. 2013. The antimosquito properties of extracts from flowering plants in South Africa. Tropical Biomed. 30(4): 559-569.

Harborne, J.B. 1987. Metode Fitokimia, Edisi ke dua. ITB, Bandung.

Kantheti, P., Padma A. 2017. Ethnobotanical tribal practices for mosquito repellency followed by people of north India. J Pharm Phytochem. 6(6): 942-494

Kausar, M.A. 2018. A review on Respiratory allergy caused by insects. Bioinformation 14(9): 540-553

Maia, M.F., Moore S.J. 2011. Plant-based insect repellents: a review of their efficacy, development and testing. Malaria J. 10(1) : 1-15

Pichersky E, Gershenzon J. 2002. The formation and function of plant volatiles: perfumes for pollinator attraction and defense. Curr Opinion Plant Biol. 5:237-243.

Qiu, H., Jun H.W., McCall J.W. 1998. Pharmacokinetics, formulation, and safety of insect repellent, N,Ndiethyl-3-methylbenzamide (deet): a review. J Am Mosq Control Assoc 14:12-27

Raina. 2011. Ensiklopedi Tanaman Obat untuk kesehatan. Cetakan 1. Yogyakarta Absolut.

Rialita, T., Rahayu W.P., Nuraida L., Nurtama B. 2015. Aktivitas antimikroba minyak esensial jahe merah (Zingiber officinale var. Rubrum) dan lengkuas merah (Alpinia purpurata K. Schum) terhadap bakteri patogen dan perusak pangan. J AGRITECH. 35(1):43-52. 
Hasan, S., Taher, D.M., Tamalene, M.N. 2020. Tumbuhan anti-nyamuk, masyarakat kepulauan, pengetahun lokal

Shankar, B.S., Saravanan T., Ragavi M., Kaviya G., Anushree A., Samraj D.A., Tennyson S. 2013. Screening of Local Plants for Their Repellent Activity against Mosquitoes (Diptera: Culicidae). J Mosquito Res. Vol.3(14): 97-104.

Taher, D.M., Nurhasanah, Papuangan N. 2015. Potensi cengkeh (Syzygium aromaticum) varietas Afo sebagai larvasida alami nyamuk Anopheles subpictus dan Aedes aegypti. Masyarakat Biodiversitas Indonesia, PROS SEM NAS MASY BIODIV INDON. 1(6): 1478-1482

Taher, D.M., Solihin D.D., Cahyaningsih U., Sugita P. 2019. Chemical Components Analysis Of Clove (Syzygium aromaticum (L). Merr. \& Perry). Global Science J. 7 (4)

Tefera, B.N., Kim Y.D. 2019. Ethnobotanical study of medicinal plants used as antimalarial and repellent by Sidama people of Hawassa Zuria district, Southern Ethiopia. J Complement Med Res. Vol 10 (1) : 13-26

Youmsi, R.D.F., Fokou P.V.T., Menkem E.Z., Bakarnga-Via I., Keumoe R., Nana V., Boyom F.F. 2017. Ethnobotanical survey of medicinal plants used as insects repellents in six malaria endemic localities of Cameroon. J Ethnobiol etnomed. 13 (33): 1-14 